BBA 5594I

\title{
INCORPORATION OF RICINOLEIC ACID INTO GLYCEROLIPIDS
}

\author{
E. D. BARBER, W. L. SMITH AND W. E. M. LANDS
}

Department of Biological Chemistry, The University of Michigan, Ann Arbor, Mich. $48{ }_{104}$ (U.S.A.)

(Received June 8th, I97I)

SUMMARY

The coenzyme A thiol ester of ricinoleic acid was synthesized and characterized.

Ricinoleoyl-CoA has been tested as an acyl donor in several in vitro systems using rat liver microsomal acyltransferases.

It is essentially inactive when I-acyl- or 2-acyl-sn-glycerol-3-phosphoryl choline are used as acceptors, however, it can serve as acyl donor when glycerol-3phosphate or I-acyl-sn-glycerol-3-phosphate are acceptors to yield di- and monoricinoleoyl glycerol-3-phosphates, respectively. A high apparent $K_{m}(50 \mu M)$ for ricinoleoyl-CoA may explain the fact that ricinoleic acid appears to be excluded from phospholipids in vivo.

\section{INTRODUCTION}

Several nutritional studies have focused upon the fate of ingested ricinoleic acid $^{1-4}$. When ricinoleic acid or triricinolein is fed to rats, the acid can be absorbed and activated to ricinoleoyl- $\mathrm{CoA}^{3}$ and subsequently incorporated into fat pad triglycerides $^{1-4}$. Depending on the nature and duration of the diet, some $5-10 \%$ of the fatty acids in the carcass triglyceride can be shown to be ricinoleic acid ${ }^{\mathbf{1 - 4}}$. In spite of this rather heavy accumulation in triglycerides, no ricinoleate is incorporated into tissue phospholipids"-4. WATSON AND MURRAY ${ }^{4}$ report that "The absence of ricinoleic acid (in phospholipids) is absolute. Excessively large samples were analysed deliberately and no trace of ricinoleic acid was found". On the basis of these results they suggested that the incorporation of ricinoleate into triglyceride may proceed via the acylation of monoglyceride ${ }^{5,6}$ rather than via the de novo or phosphatidic acid pathway ${ }^{7-9}$.

In view of the fact that ricinoleate appears to be completely excluded from mammalian phospholipids in vivo, we thought that a direct examination of the acyltransferase systems in vitro might help explain the exact mechanism of this exclusion. The purpose of this communication is to report the results of experiments in which ricinoleoyl-CoA has been synthesized, characterized and tested as a substrate for various rat liver microsomal acyltransferases ${ }^{10,11}$.

Abbreviations: DTNB, 5,5'-dithiobis-(2-nitrobenzoic acid). 
MATERIALS AND METHODS

Reagents

Ricinoleic acid (12-hydroxy-octadec-g-enoic acid) was purchased from the Hormel Institute and used without further purification. Coenzyme A was a product of Calbiochem. Silicic acid (200-325 mesh) and Silica Gel G chromatography resins were purchased from Mallinkrodt and Brinkmann, respectively. Bis-(trimethylsilyl-)trifluoroacetamide (Regisil) was obtained from the Regis Chemical Company. 5,5'Dithiobis-(2-nitrobenzoic acid) (DTNB) was a product of Aldrich Chemical Company while ethyl chloroformate was purchased from Eastman Organic Chemicals. All other solvents and reagents were obtained from commercial sources and used without further purification.

\section{Synthesis of ricinoleoyl-CoA}

Ricinoleoyl-CoA was synthesized using the mixed anhydride procedure described by KAss et al..$^{12}$.

I mmole of ricinoleic acid was dissolved in $20 \mathrm{ml}$ of tetrahydrofuran (distilled over $\mathrm{LiAlH}_{4}$ immediately before use) and treated with I mmole each of triethylamine and ethyl chloroformate at $2^{\circ}$. After $I \mathrm{~h}$, the resulting suspension was filtered and washed with tetrahydrofuran. The solution was evaporated and the residue dissolved in $2 \mathrm{ml}$ of tetrahydrofuran. This solution was added slowly to a solution of $33 \mu$ moles of coenzyme $\mathrm{A}$ ( $\mathrm{Li}^{+}$salt) in $5 \mathrm{ml}$ of tetrahydrofuran-water $(5: 2, \mathrm{v} / \mathrm{v})$; the $\mathrm{pH}$ being adjusted to $7 \cdot 5$ after each addition. The reaction was judged complete when an aliquot of the reaction mixture failed to produce a yellow color when added to I MM DTNB in o.I M Tris- $\mathrm{HCl}$ buffer ( $\mathrm{pH} 7.4$ ).

After removal of tetrahydrofuran under vacuum, ricinoleoyl-CoA was precipitated by adjusting the solution to $1 \% \mathrm{HClO}_{4}$. The aqueous suspension was extracted several times with diethyl ether and the precipitate was finally collected by centrifugation and then redissolved in $3 \mathrm{ml}$ of deionized water and made to $\mathrm{pH} 5.0$ with $\mathrm{NaHCO}_{3}$. The solution was divided and stored frozen at $-10^{\circ}$. The yield of ricinoleoyl-CoA based on the initial amount of $\mathrm{CoA}$ was $80 \%$.

\section{Characterization of ricinoleoyl-CoA}

Concentrations of adenine and thiol ester were calculated from absorbances at 260 and $232 \mathrm{~nm}$, respectivcly, using the extinction coefficients given by SEUBERT ${ }^{13}$. The concentration of thiol ester was also estimated by determining the amount of free CoA liberated from aliquots of the ricinoleoyl-CoA solution by pancreatic lipase ${ }^{14}$.

Phosphate analyses were performed by the method of EIBL AND LANDS ${ }^{15}$ following acid digestion for 90 min at $190^{\circ}$ in the presence of $3 \mathrm{M} \mathrm{H}_{2} \mathrm{SO}_{4}$.

Aliquots of the ricinoleoyl-CoA solution were transesterified using $0.5 \mathrm{M}$ sodium methoxide in methanol and the resulting methyl esters were extracted into petroleum ether. After evaporation of the solvent under a stream of $\mathrm{N}_{2}, 50 \mu 1$ of bis-(trimethylsilyl-) trifluoroacetamide was added in order to silylate the hydroxyl groups. After 30 min at $40-50^{\circ}$, the silylating reagent was removed under $\mathrm{N}_{2}$, the samples dissolved in $50 \mu \mathrm{l}$ of $\mathrm{CS}_{2}$ and analysed by gas-liquid chromatography as described by BRANDT AND LANDS ${ }^{16}$. The column temperature was $197^{\circ}$ and the carrier gas used was $N_{2}$.

Ricinoleic acid was quantitatively determined by hydrolysis of aliquots of the 
ricinoleoyl-CoA solution using I.o $\mathrm{ml}$ of o.I $\mathrm{M} \mathrm{NaOH}$ in methanol-water $(4: \mathrm{I}, \mathrm{v} / \mathrm{v})$ at $80^{\circ}$ for $30 \mathrm{~min}$ followed by chromatography on thin layers of Silica Gel $\mathrm{G}$ with benzene-dioxane-acetic acid-88\% formic acid ( $82: \mathrm{I} 4: \mathrm{I}: \mathrm{I}$, by vol.) as the developing solvent. The thin-layer chromatographic plates were sprayed with $50 \% \quad \mathrm{H}_{2} \mathrm{SO}_{4}$ and charred for $30 \mathrm{~min}$ on an electric hotplate. The density of the spots was determined using a Photovolt model 520 recording densitometer fitted with a narrow slit adapter. Recorder response number 5 was used throughout and the amplifier setting was either number I or 2 . Before each determination, the zero and full scale values on the recorder were calibrated with the light source at full intensity and at zero intensity, respectively, using an area of the plate on which no spots appeared. Quantitation was achieved via reference to a standard curve generated by an identical procedure using known amounts of ricinoleic acid ${ }^{17}$. Peak areas were determined by triangulation in all cases.

\section{Acyltransferase studies}

The enzyme preparation used was a washed crude microsomal fraction of rat liver prepared and stored as described by EIBL et al. ${ }^{18}$. Acyl-CoA: I-acyl-sn-glycerol-3phosphoryl choline acyl-transferase, acyl-CoA : 2-acyl-sn-glycerol-3-phosphoryl choline acyltransferase and acyl-CoA: I-acyl-sn-glycerol-3-phosphate acyl- transferase activities were measured using the spectrophotometric assay system described by LANDS AND HART ${ }^{18}$. I-Acyl-sn-glycerol-3-phosphoryl choline was prepared by venom-catalysed hydrolysis of diacyl-sn-glycerol-3-phophoryl choline whereas 2-acyl-sn-glycerol3-phosphoryl choline was prepared by iodine cleavage of I-alkenyl-2-acyl-sn-glycerol-3-phosphoryl choline as described previously ${ }^{20}$. I-Acyl-sn-glyccrol-3-phosphate was prepared by phospholipase D catalysed hydrolysis of I-acyl-sn-glycerol-3-phosphoryl choline (see ref. 20).

Phosphatidate synthesis from $s n$-glycerol-3-phosphate was studied using the incubation system described previously ${ }^{11}$ with either $\left[{ }^{3} \mathrm{H}\right]$ glycerol-3-phosphate or $\left.{ }^{[14} \mathrm{C}\right]$ oleoyl-CoA. The lipid products were chromatographed on thin layers of silicic acid using chloroform-ethanol-88\% formic acid-water (I0o: I I:3:0.25, by vol.) as the developing solvent. Standard preparations of monoacyl-glycerol-3-phosphate and diacyl-glycerol-3-phosphate (prepared by phospholipase hydrolysis of egg lecithin) were added before chromatography. Thin layer chromatographic plates were visualized briefly with $\mathrm{I}_{2}$ vapor, decolorized overnight and the fractions were scraped directly into scintillation vials and counted using the fluid system described by SNYDER ${ }^{21}$.

\section{RESULTS}

\section{Characterization of ricinoleoyl-CoA}

Results obtained from the various chemical and enzymatic analyses of ricinoleoyl-CoA and oleoyl-CoA are summarized in Table I. The phosphate: thiol ester : adenine : fatty acid ratios were $3 . I 7:$ I.02 : I.23 : I.o for oleoyl-CoA and 2.68: 0.88 : $0.99:$ I.o for ricinoleoyl-CoA. These values compare favorably with the $3: 1: I: I$ ratio expected for pure acyl-CoA. Neither acyl-CoA solution contained significant amounts of free $\mathrm{CoA}$ as evidenced by the fact that no increase in the absorbance at $4 \mathrm{I} 3 \mathrm{~nm}$ was observed in the absence of pancreatic lipase when aliquots were added to I $\mathrm{mM}$ DTNB. 


\section{TABLE I}

RESULTS OF CHEMICAL AND ENZYMATIC ANALYSIS OF OLEOYL AND RICINOLEOYL COA

All results are quoted as $\mu$ moles/ml of each stock solution. Analyses performed as stated under METHODS. Each value is reported as mean \pm S.E. and the numbers in parentheses are the numbers of analyses which have been included.

\begin{tabular}{|c|c|c|c|c|c|c|}
\hline \multirow[t]{2}{*}{$A c y l-C o A$} & \multirow{2}{*}{$\begin{array}{l}\text { Phospho- } \\
\text { rus }\end{array}$} & \multicolumn{3}{|l|}{ Thiol ester } & \multirow{2}{*}{$\begin{array}{l}\text { Adenine } \\
260 \mathrm{~nm}\end{array}$} & \multirow{2}{*}{$\begin{array}{l}\text { Fatty } \\
\text { Acid }\end{array}$} \\
\hline & & Lipase & $232 \mathrm{~nm}$ & $\overrightarrow{\text { Average }}$ & & \\
\hline Oleoyl & $\begin{array}{l}9.78 \perp 0.5 \\
(5)\end{array}$ & $\begin{array}{l}2.64 \text { 上 } 0.06 \\
\text { (I } 5)\end{array}$ & $\begin{array}{l}3.66 \pm 0.07 \\
(4)\end{array}$ & $3 \cdot 15$ & $\begin{array}{l}3.81 \\
(4)\end{array}$ & $\begin{array}{l}3.09 \\
(4)\end{array}$ \\
\hline Ricinoleoyl & $\begin{array}{l}24.0 \pm 0.8 \\
(3)\end{array}$ & $\begin{array}{l}7.68 \pm 0.23 \\
(\mathbf{I} \mathbf{I})\end{array}$ & $\begin{array}{l}8.08 \pm 0.36 \\
(4)\end{array}$ & 7.88 & $\begin{array}{l}8.88 \pm 0.33 \\
(4)\end{array}$ & $\begin{array}{l}8.95 \\
(5)\end{array}$ \\
\hline
\end{tabular}

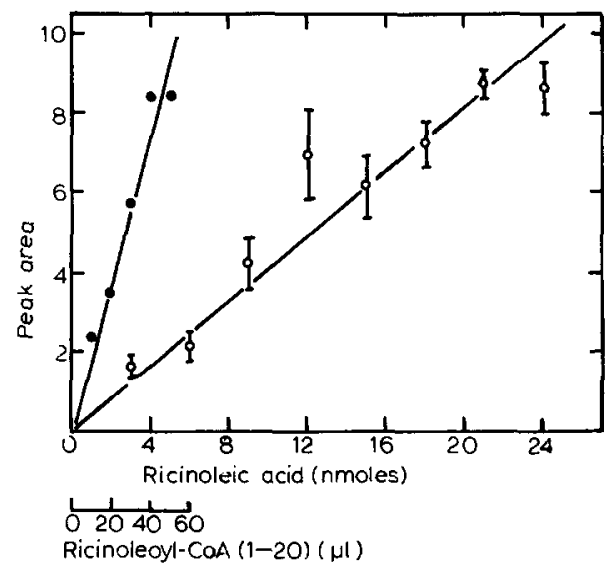

Fig. I. The peak areas (arbitrary units) obtained from densitometer tracings plotted versus the amount of ricinoleic acid and the volume of the diluted ricinolcoyl-Co $\Lambda$ solution taken for hydrolysis. Basic hydrolysis were performed for $30 \mathrm{~min}$ as described in MATERIALS AND METHODS. After neutralization, the ricinoleic acid was extracted using $4 \mathrm{ml}$ of $\mathrm{CHCl}_{3}-$ methanol $(2: \mathrm{I}, \mathrm{v} / \mathrm{v})$. The extract was washed with $4 \mathrm{ml} \mathrm{H}_{2} \mathrm{O}$ to remove methanol and $\mathrm{NaCl}$ and the $\mathrm{CHCl}_{3}$ phase was evaporated to dryness. The residue was redissolved in $100 \mu 1 \mathrm{CHCl}_{3}$ and spotted on the thin-layer chromatographic plate. Each point on the standard curve represents the mean \pm S.D. from four experiments.

The concentration of fatty acid in the two preparations was obtained from data such as those presented in Fig. I for ricinoleoyl-CoA. The area of the densitometer peaks is plotted as a function of the amount of ricinoleic acid applied to the thin-layer chromatographic plate and also as a function of the volume of the ricinoleoyl-CoA solution (stock solution diluted 2o-fold) taken for base hydrolysis and subsequent thin-layer chromatography. A reasonably linear relationship was obtained, and the concentration of ricinoleic acid was calculated from a ratio of the slopes. Oleic acid was similarly determined in basic hydrolysates of a known oleoyl-CoA solution to provide a confirmation of the validity of the methods used.

Densitometric measurements of the commercial ricinoleic acid preparation revealed two impurities representing $6 \pm \mathrm{I} \%$ of the total mass and travelling with $R_{F}$ values greater than ricinoleate in this solvent system. These impurities could not, however, be detected in basic hydrolysates of the ricinoleoyl-CoA preparation by this technique. Gas-liquid chromatography of the silylated methyl esters arising from either the standard ricinoleic acid preparation or from the ricinoleoyl-CoA failed also 
to reveal any impurities. No peaks were detected when the silylation procedure was omitted and a single symmetrical peak was observed with either the standard ricinoleic acid sample or the transesterified ricinoleoyl-CoA preparation. A single peak was also observed when the two samples were co-chromatographed, indicating the presence of a single fatty acid in the ricinolcoyl-Co $\Lambda$ preparation which co-chromatographs with authentic ricinoleic acid.

\section{Acyltransferase studies}

The rates of transfer of palmitate, oleate and ricinoleate from their CoA derivatives to the I- and 2-isomers of monoacyl-sn-glycerol-3-phosphoryl choline and to the I- isomer of monoacyl-sn-glycerol-3-phosphate were studied using the spectrophotometric assay for free CoA release ${ }^{18}$. In these experiments, microsomes, buffer, DTNB and acyl-CoA were incubated for several minutes before the addition of acceptor. Acyltransferase rates represent the net change in velocity due to addition of the acceptor. The results of these studies are shown in Tables II and III and are in reasonably good agreement with those presented by LANDS AND HART ${ }^{10}$, Hill. AND LANDS $^{22}$ and VAN DEN Bosch et al. ${ }^{23}$. In agreement with previous reports ${ }^{22,24}$ the reaction was found to be inhibited by high concentrations of either acyl-CoA or phospholipid acceptor. Therefore, concentrations of acceptors used in these experiments were selected to provide maximal acyltransferase rates in each case.

The data in Table II show that ricinoleoyl-CoA served ineffectively as a substrate in the acylation of either I- or 2-acyl-sn-glycerol-3-phosphoryl choline but can, however, serve as an effective substrate for the acylation of I-acyl-sn-glycerol-3phosphate. The maximum velocity of incorporation of ricinolcate into diacyl-snglycerol-3-phosphate is comparable to the maximum velocities observed with palmitate and oleate (Table II), however, the observed $K_{m}$ for ricinoleoyl-CoA is about $5 \circ \mu \mathrm{M}$ under these conditions (Table III) or at least 50 times the observed $K_{m}$ value for other acyl-CoA's with this enzyme ${ }^{24}$.

The acyltransferase data thus provide evidence for phosphatidate synthesis from ricinoleoyl-CoA and I-acyl-sn-glycerol-3-phosphate. We next examined phos-

\section{TABLE II}

RATES OF ACYLATION WITH PALMITOYL-, OLEOYL- AND RICINOLEOYL-COA

Rates are expressed in nmoles/min per $\mathrm{mg}$.

\begin{tabular}{|c|c|c|c|c|}
\hline \multirow[t]{2}{*}[Acyl-CoA]{,$\mu M$} & \multirow{2}{*}{$\begin{array}{l}\text { No } \\
\text { Acceptorat }\end{array}$} & \multicolumn{3}{|l|}{ Acceptor added } \\
\hline & & $\begin{array}{l}\text { I75 HM I-acyl-sn-glyc- } \\
\text { erol-3-phosphoryl choline }\end{array}$ & $\begin{array}{l}7^{2} \mu M \text { 2-acyl-sn-glyc- } \\
\text { orol-3-phosphoryl choline }\end{array}$ & $\begin{array}{l}75 \mu M I-a c y l-s n-g l y c- \\
\text { erol-3-phosphate }\end{array}$ \\
\hline $16: 0$, I 3 & $17 \cdot 3(2)$ & 一 & 27.0 & 53.7 \\
\hline $16: 0,27$ & $29.1(2)$ & 2.7 & I9.5 & 40.8 \\
\hline $16: 0,4^{\circ}$ & $30.5(2)$ & 2.7 & I6.7 & $33 \cdot 4$ \\
\hline $\mathbf{I} 8: \mathrm{r}, \mathrm{r} 3$ & $5.8(2)$ & $36 . I$ & I8.9 & 38.7 \\
\hline I $8: 1,25$ & $9.7(2)$ & 30.6 & I6.5 & $45 \cdot 7$ \\
\hline I $8: \mathrm{x}, 38$ & $12.3(2)$ & $27 . \mathrm{I}$ & I 5.1 & $5 \mathrm{I} . \mathrm{I}$ \\
\hline HO I $8: x, \quad 39$ & $6.9(3)$ & I.8 & $-\mathrm{I}, 2^{\mathrm{b}}$ & 50.1 \\
\hline HO $x 8: x, 77$ & $6.7(3)$ & I. 5 & $-\mathrm{I} .2$ & $4^{6.4}$ \\
\hline $\mathrm{HO} 18: \mathrm{x}, \mathrm{II}$ & $6.9(3)$ & 0.6 & -0.7 & 62.3 \\
\hline
\end{tabular}

Acyl-CoA hydrolase or transfer to endogenous acceptors; average of at least 2 determinations.

b Slower rate observed after addition of the acceptor. Acyl-CoA hydrolase can be partially inhibited by the presence of detergents ${ }^{18}$. Hence the negative rate results because the inhibition of hydrolase was numerically greater than the action of acyltransferase. 


\section{TABLE III}

RATES OF ACYLATION OF I-ACYL- $n$-GLYCEROL-3-PHOSPHATE AT VARTOUS CONCENTRATIONS OF PALMITOYL-, OLEOYL- AND RICINOLEOYL-COA

Rates are expressed in nmoles/min per $\mathrm{mg}$.

\begin{tabular}{|c|c|c|}
\hline \multirow{2}{*}[Acyl-CoA]{$\times \mu M$} & \multicolumn{2}{|c|}{ Acceptor added } \\
\hline & None $e^{\mathrm{a}}$ & $\begin{array}{l}55 \mu M r \text {-acyl-sn-glyc- } \\
\text { evol-3-phosphate }\end{array}$ \\
\hline $16: 0,9$ & 4.9 & 20.7 \\
\hline $16: 0,18$ & 6.7 & $15 \cdot 4$ \\
\hline $16: 0,27$ & 8.7 & 19.4 \\
\hline $16: 0,36$ & I 1.8 & 4. \\
\hline $16: 0,54$ & $\times 5.2$ & $-1 \cdot I^{b}$ \\
\hline $16: 0,90$ & $x 3.5$ & -5.7 \\
\hline $18: 1,9$ & 2.9 & I $3 \cdot I$ \\
\hline $18: 1$, I 9 & 3.8 & 15.0 \\
\hline $18: 1,31$ & 6.4 & 20.8 \\
\hline $\mathbf{x} 8: \mathbf{1}, 63$ & 6.8 & I 8. I \\
\hline I $8: 1,94$ & 6.5 & II, 4 \\
\hline $\mathrm{HO}, 8: \mathrm{T}, \quad 8$ & 2.0 & $5 \cdot 1$ \\
\hline HO I $8: 1, \quad$ I6 & 2.3 & 11.0 \\
\hline $\mathrm{HO}$ I $8: 1, \quad 3^{2}$ & 2.8 & $17 \cdot 3$ \\
\hline HO I $8: 1, \quad 56$ & 2.8 & 23.8 \\
\hline $110 \mathrm{r} 8: \mathbf{r}, 8 \mathbf{r}$ & $4 . I$ & 25.6 \\
\hline HO I $8: \mathbf{I}, \mathbf{I} 2 \mathrm{I}$ & 3.8 & 27.8 \\
\hline HO I $8: 1, I 62$ & 3.8 & $23 . I$ \\
\hline
\end{tabular}

a sce footnote, Table II.

b see footnote Table II.
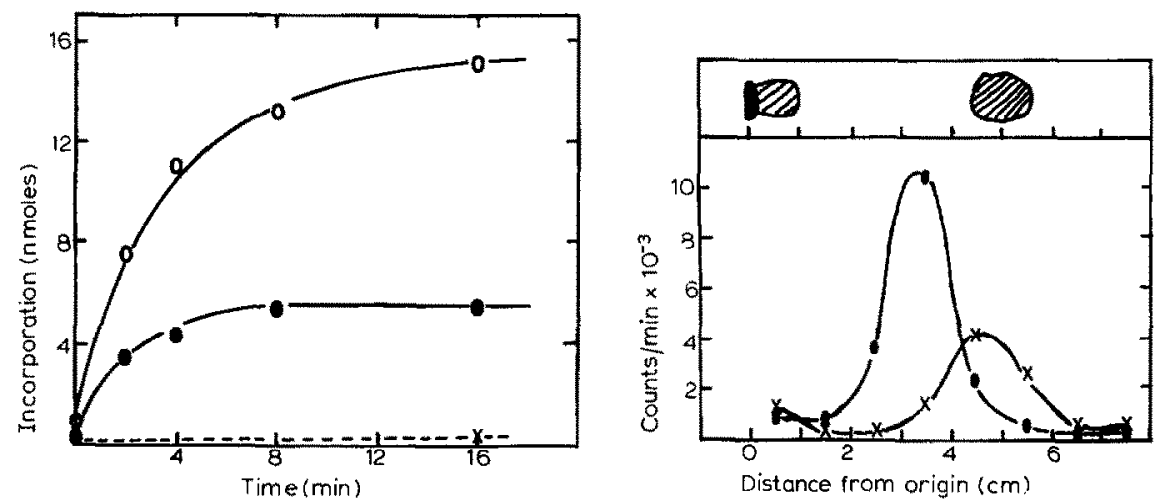

Fig. 2. Amount of oleate $(O-0)$ or glycerol-3-phosphate (-) incorporated into chloroformsoluble lipids versus time. In Curve A $(0-0)$, 16 mmoles of $\left[{ }^{14} \mathrm{C}\right]$ oleoyl-CoA (specific activity $=502$ counts/min/nmole) and 200 nmoles of glycerol-3-phosphate were incubated with rat liver microsomes ( $1.4 \mathrm{mg}$ protein) in the incubation system described by Hill et al.17. In curve B (-) 18 nmoles of ricinoleoyl-CoA was present with 165 nmoles $\left[{ }^{3} \mathrm{H}\right]$ glycerol-3-phosphate (2020 counts $/ \mathrm{min} / \mathrm{nmole})$ and Curve $\mathrm{C}(---)$ shows results without added acyl-CoA, but included $I 65$ nmoles $\left[{ }^{3} \mathrm{H}\right]$ glycerol-3-phosphate as in $B$.

Fig. 3. The distribution of radioactive lipid on thin-layer chromatography. Aliquots from the 4-min incubations from $\mathrm{A}$ and $\mathrm{B}$ of Fig. 2 were pooled and chromatographed, on the thin-layer chromatographic system described in METHODs. The migration of standard mono- $(0.5 \mathrm{~cm})$ and di-acyl-snlglycerol-3-phosphate $(5 \mathrm{~cm})$ are shown at the top of the figure.

The standards and radioactive products were chromatographed in adjacent lanes and hence $R_{F}$ values are not exactly comparable. Ricinoleoyl-CoA plus $\left[{ }^{3} \mathrm{H}\right] g l y c e r o i p h o s p h a t e(-0)$ and $\left[{ }^{4} \mathrm{C}\right.$ joleoyl-CoA plas unlabelled glycerolphosphate $(\mathrm{x}-\mathrm{x})$ are shown. 
phatidate synthesis from acyl-CoA and $s n$-glycerol-3-phosphate to see if ricinoleoylCoA could serve as an acyl donor for the acyl-CoA : glycerol-3-phosphate acyltransferase as well.

\section{Incorporation of glycerolphosphate}

Studies of phosphatidate synthesis were carried out by incubating microsomes with labelled acyl-CoA or labelled $s n$-glycerol-3-phosphate as described in methods and chromatographing the products on silicic acid. The plates were divided into $\mathrm{I}-\mathrm{cm}$ fractions and the fractions scraped into scintillation vials for counting. Fig. 2 shows the total incorporation into lipids as a function of time when (a) $\left.{ }^{\left[{ }^{14}\right.} \mathrm{C}\right]$ oleoylCoA plus unlabelled sn-glycerol-3-phosphate, and (b) ricinoleoyl-CoA plus $\left[{ }^{3} \mathrm{H}\right] s n$ glycerol-3-phosphate are incubated in separate experiments with rat liver microsomes $(\mathrm{r} .4 \mathrm{mg})$. It is clear from these data that ricinolenyl-CoA stimulates the incorporation of labelled glycerolphosphate into lipids. Curve $\mathrm{C}$, in which $\left[{ }^{3} \mathrm{H}\right]$ sn-glycerol-3-phosphate but no acyl-CoA was used, shows that the level of endogenous acyl donors is very low.

After the incubations, the extracts from each time point were pooled, chromatographed and counted. Fig. 3 shows the resulting chromatogram obtained from the 4 -min incubations. It is clear that the lipid containing ricinoleate moves with an $R_{F}$ different from that containing oleate.

\section{DISCUSSION}

From the data presented in this report, it can be concluded that ricinoleoyl$\mathrm{CoA}$ is capable of serving as an acyl donor in the acylation of glycerolphosphate or of I-acylglycerolphosphate to form either a di- or mono-ricinoleoyl derivative, respectively. Hence, the evidence suggests that ricinoleate might be incorporated into phosphoglycerides via the de nov ${ }^{8}$ pathway. In contrast to this finding, the experiments using monoacyl-sn-glycerol-3-phosphoryl choline as acceptor, suggest that ricinoleate can not enter the lecithin pool via the acyltransferase "retailoring" route 25 . Thus these in vitro assays did not give a single, clear explanation for the mechanism by which ricinoleate is excluded from phosphoglycerides in wivo. Previnus reports have shown that the observed specificity of phosphatidate synthesis in vitro need not be the same as that prevailing in vivo or in tissue slices ${ }^{10,11,26,27}$. In vitro, the newly synthesized phosphatidate displays a random fatty acid composition ${ }^{11}$ whereas the asymmetric distribution of saturated and unsaturated fatty acids esterified at the I- and 2 -positions of phosphatidates in vivo is quite striking ${ }^{11}$. Hence, there is reason to believe that the lack of specificity observed in cell-free systems may not reflect accurately that expressed in vivo, although several recent reports have now described non-random acylation in vitro ${ }^{28,29,32,33}$.

In the spectrophotometric studies, all of the added acyl-CoA appears as free $\mathrm{CoA}$ and thus we are seeing essentially $100 \%$ of the thiol esters responding to enzymic catalysis. All time curves for CoA release were smooth, with no evidence of any biphasic response. In addition, it can be calculated from the data in Fig. 2 that $62 \%$ of the added ricinoleate was incorporated into diacyl-sn-glycerol-3-phosphate. Furthermore, the lower $R_{H^{*}}$ value for the resultant phosphatidate was expected for a phosphatidate of greater polarity. Thus we can be confident that the conclusions 
drawn from the present data are not due to an impurity, but based on the effects of ricinoleate transfer.

Similar $R_{F}$ values were noted for all time points studied. By comparison with standard lipids (Fig. 3, top) we conclude that diricinoleoyl-sn-glycerol-3-phosphate and dioleoyl-sn-glycerol-3-phosphate were formed in vitro. Several papers have indicated that hydroxystearic acid ${ }^{30}$ and 9 -hydroxy octadecadienoic acid ${ }^{31}$ are rapidly converted to non-hydroxy fatty acids in the liver presumably by oxidation to acetate and resynthesis. It would therefore appear that the lifetime of hydroxy fatty acids in this tissue is very short $\left(t_{1 / 2}<5 \mathrm{~min}\right)$ and this rapid breakdown perhaps causes a very low steady-state concentration of hydroxy acids in liver. Such a low steady state level in combination with a high $K_{m}$ (such as that seen for the acylation at the 2-position) value for ricinoleoyl-CoA in the acylation reaction thus appears to be the most reasonable explanation for the exclusion of ricinoleate from phospholipids in vivo.

The above hypothesis provides for the exclusion of ricinoleate from the I- and 2-positions of all phosphoglycerides, but leaves undetermined the ability of ricinoleoyl-CoA to be esterified to the 3-position of I,2-diacylglycerols. The enzyme catalyzing that esterification may not be as selective as others (i.e. it may have similar $K_{m}$ values for all acyl-CoA esters). This concept is supported by the appearance of butyrate at the 3 -position in milk fat ${ }^{34}$ and the more abundant long-chain unsaturated acids at that position in liver triacylglycerols ${ }^{35}$. Even the observation that most long-chain acids appear at the primary position ${ }^{36}$ could be due to their entry into glycerides at the 3-position. The acylation at the 3-position may be the principal site of entry of rincinoleate into glycerides in vivo. Unfortunately, the opportunity for randomization of the acids at the I- and 3-positions during storage in tissue depots prevents a clear understanding of biosynthetic selectivities from simple analyses of tissue lipid isomers.

\section{ACKNOWLEDGMENTS}

These studies were supported by U.S. Public Health Service grant number AM-053IO. E. B. is a post-doctoral fellow of National Institutes of Health, fellowship number I-FO2-NS48, 504-or NSRB and W. S. is supported by U.S. Public Health Service Research Training Grant GM-ooI87.

\section{REFERENCES}

1 W. C. Stewart and R. G. Sinclair, A*ch. Biochem., 8 (1945) 7 .

2 E. G. Perkins, J. G. Endres and F. A. Kummerow, J. Nutr, 73 (Ig6r) 29 I.

3 W. C. Watson and R. S. Gordon JR., Biochem. Pharmacol., I I (1962) 229.

4 W. C. Watson and E. S. Murray, Biochim. Biophys. Acta, 106 (1964) 3 II.

5 B. Clark and G. Hubscher, Biochim. Biophys. Acta, 7o (I963) 43.

6 J. R. Senior and K. J. Isselbacher, Biochim. Biophys, Acta, 44 (rg6o) 399.

7 A. Kornberg and W. E. Pricer, J. Biol. Chem., 204 (1953) 345.

8 E. P. Kennedy, J. Biol. Chem., 201 (1953) 399.

9 A. M. DAwSON AND K. J. IsSElbacher, J. Clin. Invest., 39 (I960) I 50 .

ro W. E. M. Lands, J. Biol. Chem., 235 (1960) 2233.

I E. E. Hill, D. R. Husbands and W. E. M. Lands, J. Biol. Chem., 243 (I968) 4440.

I 2 L. R. Kass, D. J. H. BRock AND K. Bloch, $J$. Biol. Chem., 242 (1967) 44T8.

3 W. SEUBert, Biochem. Prep., 7 (1960) 80 .

14 E. D. Barber and W. E. M. LANDS, Biochim. Biophys. Acia, 250 (197I) in the press.

Biochim. Biophys. Acta, 248 (I97I) I 7 I-I 79 
I5 H. Eibl and W. E. M. Lands, Anal. Biochem., 30 (1969) 5 I.

I6 A. E. BRandt and W. E. M. Lands, Lipids, 3 (I968) I 78.

i 7 O. S. Privett, M. L. Blank, D. W. Codding and E. C. Nickel, J. Am. Oil Chemists' Soc., $42(\mathrm{I} 965) 38 \mathrm{I}$.

I 8 H. Eibl, E. E. Hill and W. E. M. Lands, Eur. J. Biochem., 9 (I969) 250.

19 W. E. M. Lands and P. Hart, J. Biol. Chem., 240 (1965) 1905.

20 H. Okuyama, W. E. M. Lands, W. W. Christie and F. D. Gunstone $J$. Biol. Chem., 244 (1969) 65I4.

21 F. SNYDER, Anal. Biochem., 9 (1965) I83.

22 E. E. Hill and W. E. M. Lands, Biochim. Biophys. Acta, I 52 (1968) 645 .

23 H. Van den Bosch, L. M. G. Van Golde, H. Eibl and L. L. M. Van Deenen, Biochim. Biophys. Acta, I44 (1967) 613.

24 R. E. Barden and W. W. Cleland, J. Biol. Chem., 244 (1969) 3677.

25 W. E. M. Lands, J. Biol. Chem., 235 (1960) 2233.

26 E. Sánchez de Jiménez and W. W. Cleland, Biochim. Biophys. Acta, i76 (1969) 685.

27 H. M. Abou-Issa and W. W. Cleland, Biochim. Biophys. Acta, i 76 (I969) 692.

28 F. Possmayer, G. L. Scherphof, T. M. A. R. Dubbelman, L. M. Van Golde and L. L. M. Van Deenen, Biochim. Biophys. Acta, i 76 (Ig69) 95.

$29 \mathrm{H}$. OKuYama and W. E. M. Lands, in preparation.

3o J. Elovson, Biochim. Biophys. Acta, 84 (I964) 275.

3 I R. J. Reber and H. H. Draper, Lipids, 5 (I970) 983.

32 T. K. Ray, J. E. Cronan JR., R. D. Mavis and P. R. Vagelos, J. Biol. Chem., 245 (I970) $644^{2}$.

33 H. Van Den Bosch and P. R. Vagelos, Biochim. Biophys. Acta, 2 I 8 (1970) 233.

34 W. C. BRECKENRIDGE AND A. Kuksis, Lipids, 4 (I969) I 97.

35 S. P. M. Slakey and W. E. M. Lands, Lipids, 3 (I968) 30.

36 F. H. Matison and R. A. Volpenhein, J. Biol. Chem., 236 (Ig6I) I 89 I. 